\title{
Compreender o mundo a partir da escrita e da leitura
}

https://doi.org/10.34112/2317-0972a2020v38n78pg-11

Anderson Ricardo Trevisan ${ }^{1}$

Renata Aliaga ${ }^{2}$

A edição 78 de Leitura: Teoria \& Prática trata de um tema Caro ao nosso universo: a apropriação da cultura escrita e a formação de leitores e autores durante o processo de alfabetização. Embora seja assunto bastante visitado, como explica Greice Ferreira da Silva, professora da Universidade Estadual de Londrina e organizadora do dossiê, o tema aqui é tratado com frescor e rigor teórico, sendo uma honra tê-lo recheando as páginas de nossa revista.

Nos cinco artigos apresentados, delineia-se um caminho instigante de discussão sobre o processo de formação de leitores e autores, a partir de resultados de pesquisa calcados em refinada discussão teórica e epistemológica, de forma crítica e não dissociada da relação com o contexto histórico e social. Assim, das proposições teóricas de Jakubinskij, Vološinov, Bakhtin e Foucambert, seguimos para a importância do lúdico no desenvolvimento da linguagem escrita, onde Vigotsky fornecerá as bases da discussão sobre o papel do faz-de-conta nesse processo. $\mathrm{Na}$ sequência, teremos relevante discussão acerca da literatura indígena na formação de leitores, que antecede o artigo sobre a obra de Monteiro Lobato, que discute os sentidos de sua ausência atual nas escolas de ensino fundamental. O dossiê,

1. Universidade Estadual de Campinas, Campinas, SP, Brasil.

2. Instituto Federal de São Paulo, Campinas, SP, Brasil. 
que será apresentado por sua organizadora de forma muito mais apropriada nas páginas que seguem, termina como uma discussão metodológica sobre o processo de apropriação da escrita na escola no início do ensino fundamental. Cinco artigos e uma discussão refinada e contemporânea que se revela como uma contribuição inquestionável para a revista LTP.

Mas ainda tem mais! A revista traz ainda cinco textos, sendo quatro artigos originais e uma resenha.

Partindo de entrevistas com professoras e resultados de pesquisa, o artigo de Cláudia Beatriz de Castro Nascimento Ometto e Renata Cristina Oliveira Barrichelo discute o processo de formação de professores de Salas de Leitura na rede estadual paulista, buscando compreender como esses profissionais se apropriam das experiências de formação e (re)organizam suas concepções e práticas.

Graciliano Ramos aparece através de seus contos "Minsk" e "Luciana", publicados em 1974, nas análises de Fabíola Ribeiro Farias, Luiz Percival Leme Britto e Zair Henrique Santos. Partindo das ilustrações presentes nesses textos, os autores revelam a centralidade das imagens na caracterização do livro infantil, que estariam muito além de simples acessórios. Ao contrário, as imagens teriam o papel de reinventar sentidos e criar narrativas, transformando texto e imagens em uma escrita híbrida.

Catia Silvana da Costa e Maria Iolanda Monteiro nos levam de volta ao universo da aquisição da escrita e da leitura, amparadas em resultados de uma pesquisa de mestrado que faz um entrecruzamento entre a formação de leitores/autores e as aulas de Educação Física, discutindo como diferentes linguagens são subsidiadas pela linguagem corporal.

O último artigo, assinado por Nayara Stefanie Mandarino Silva, discute, a partir da obra The wizard of $\mathrm{Oz}$ (L. Frank Baum, 1983), a importância da literatura nas aulas de inglês, sendo o texto a apresentação de resultados alcançados no PIBID/Inglês, vinculado à Universidade Federal de Sergipe.

O número 78 de LTP termina com a resenha de Cristiane Fatima Silveira sobre o livro Elogio da escola, organizado em 2017 pelo filósofo espanhol Jorge Larrosa, que discute a existência de uma "linguagem escola" que deve ser analisada, tendo em vista se valorizar o espaço escolar, em oposição à abundância de críticas que ele tem sofrido nos últimos tempos.

Como vemos, este número traz discussões de extrema relevância que, de algum modo, apontam a importância de se pensar o lugar da escola na contemporaneidade, seu papel na formação não apenas de leitores ou escritores, mas de sujeitos críticos 
capazes de compreender a realidade ao seu redor. Afinal, o primeiro passo para se transformar uma realidade é compreendê-la. Como nos lembra Raymond Williams: "A crise humana é sempre uma crise de compreensão: o que verdadeiramente compreendemos, podemos fazer".

Tempos como o que vivemos, em que estranhamente precisamos reiterar a importância de uma sociedade democrática, a escola é um espaço essencial na formação de mentes críticas que não apenas saibam decifrar textos e imagens, mas tenham condições de "ler" o mundo ao seu redor, para que possam se posicionar e serem agentes do seu próprio futuro.

Por fim, fomos presenteados pela leveza da arte de Marli Wunder, que ilustrará nossas capas nas edições deste ano. Em nome da Associação de Leitura do Brasil, agradecemos pela parceria!

3. WILlIAMS, Raymond. Cultura e sociedade, São Paulo: Companhia Editora Nacional, 1969, p. 346. 